\title{
Democracy of the Future. Comment on "Proposals for a Democracy of the Future" by Bruno Frey
}

\author{
Jarosław Kantorowicz ${ }^{1}$
}

Received: 24 April 2017/Accepted: 22 May 2017/Published online: 7 July 2017

(C) The Author(s) 2017. This article is an open access publication

\begin{abstract}
This short comment gives several directions on how Bruno Frey's ideas on a democracy of the future could be further developed. It also asks a few questions with the aim of stimulating further discussion. Some examples are derived from the recent Turkish constitutional referendum and the current parliamentary situation in Poland.
\end{abstract}

Keywords Direct democracy $\cdot$ Referendums $\cdot$ Random decisions $\cdot$ Elections

JEL Classification D02 - D70 - D72 - H10

On April 16, 2017, a slim majority of 51.4\% of voting Turks supported a constitutional amendment aimed at empowering the president vis-à-vis other branches of government (CNN Türk 2017). ${ }^{1}$ In effect, this implies a transition from the current parliamentary to a presidential system of governance. ${ }^{2}$ Some 1.4 million ballots turned out to be decisive not only in directing the path of internal affairs in Turkey, but arguably the geopolitical situation of the entire region. (Note that

\footnotetext{
1 These are the official results. Nonetheless, there are some voices that elections were not assessed correctly.

2 The president will be able to, inter alia, publish a decree, which can be recalled only by a fresh parliamentary legislation, appoint 5 out of 13 judges of the Supreme Court, and under some circumstances dissolve the parliament.
}

Jarosław Kantorowicz

j.j.kantorowicz@fgga.leidenuniv.nl

1 Institute of Security and Global Affairs, Leiden University, Wijnhaven Building, Turfmarkt 99, 2511 DP The Hague, The Netherlands 
Turkey is a member of NATO, it controls the inflow of refugees to Europe, and it is pivotal for peace in the Middle East). One could, of course, ask whether it is fair that some 25.2 million Turks 'imposed' their view on the huge minority of approx. 23.8 million of people, who opposed the system overhaul.

Bruno Frey proposes two institutional solutions, which may potentially mitigate the unfairness of political outcomes in narrow races. First, he offers that "the closer the outcome of a popular referendum is, the stronger should the representatives of the opposing parties engage in a constitutionally sanctioned procedure to reach a consensus which is then again put to the vote of the electorate" (proposal 6.7). This proposal arguably requires a certain political culture; first, to endogenize this institutional procedure in a constitution and, second, to de facto enforce it at the post-constitutional level (for endogenous direct democracy institutions see, for instance, Blume et al. 2014). This kind of reconciliation mechanism is not unknown in political process. In fact, one could draw an analogy between Frey's institutional proposal and the navette system employed in several jurisdictions to reach a consensual agreement between two chambers in bicameral parliaments or the consensual decision-making process in the Council of the European Union. ${ }^{3}$ For institutional variety of the navette mechanism see Tsebelis and Money (1995), Tsebelis and Rasch (1995). The navette system consists of sending the modified version of a bill from one of the chambers to the other. If, after several rounds, an agreement is not reached, a joint committee may be called upon to seek a compromise, as is the system in Germany. ${ }^{4}$ Thanks to this mechanism, even relatively weak upper chambers of parliament are able to obtain significant concessions from powerful lower chambers, biasing policies toward the status quo. If applied in post-referendum circumstances, this consensual/reconciliation mechanism of reaching an agreement would arguably make political and institutional change incremental. This would prevent any abrupt changes and sharp discontinuities in policy-making, hence precluding situations such as the one occurring in Turkey.

The second solution offered by Bruno Frey is an introduction of a random process of determining policies and institutional choices, wherein random refers to mathematical probability. In fact, randomization was and still is perceived as a policy tool guaranteeing fairness when it is applied to define policy choices or select policy beneficiaries. See, for instance, a disciplinary practice to punish cowardly behavior in the Roman Army, ${ }^{5}$ or more contemporary military drafts, jury selection methods, and allocation of judges to cases [for an overview see Dodge (2012), chapter 20]. Yet, at a higher political level, where elitist politics prevail, randomization as a decision-making procedure is largely missing.

Bruno Frey's proposal states that "the outcome of a popular referendum can be determined by lot with the weights given by the vote shares" (proposal 6.8). In the

\footnotetext{
${ }^{3}$ Pursuant to Article 294 (10) of the Treaty on the Functioning of the European Union (TFEU), a Conciliation Committee may be set up to resolve any disagreements between the Council of the European Union and the European Parliament under the ordinary legislative procedure.

${ }^{4}$ See Art. 53a of the Basic Law for the Federal Republic of Germany of 1949.

5 When a unit was found to retreat from a battlefield, capital punishment was imposed randomly on $10 \%$ of the unit's members. The word 'decimate' originates from this practice (Dodge 2012, p. 243).
} 
case of Turkey, instead of a definitive 'yes' or 'no' to the proposed constitutional change, the referendum would therefore determine the ex-ante probability of the system change. Since the transition of the governance system was supported by $51.4 \%$, this weight would be given to this policy option, while $48.6 \%$ would be assigned to retaining the existing system. To illustrate, a policy choice would be ultimately determined by a random selection from an urn with 514 green and 486 red balls, which indicate either a change to the presidential system or a lack thereof, respectively. This procedure has the obvious advantage of taking into consideration the size of the majority (and minority) in determining the likelihood of policy change.

It should also be stressed that the application of a random procedure arguably will not be neutral for the electoral turnout. One should note that in the proposed system all votes matter as they translate into higher ex-ante probabilities of given options. This, by itself, may incentivize voters to cast ballots and positively affect the turnout. As a result, the random procedure may minimize a pool of voters who do not cast ballots for the reason that their 'votes do not count' (their votes are not decisive).

If we further assume that abstention from voting signifies indifference toward a suggested policy change (i.e. policy choices are too alike to justify the cost of voting), one could consider extending Frey's proposal to readily take into account the size of abstention (indifference). ${ }^{6}$ Indifference was found to motivate significant amount of voter abstention, for instance, in the US presidential elections (Zipp 1985; Adams et al. 2006). A refined proposal is illustrated using the example of the Turkish referendum. The turnout in the constitutional referendum was roughly $85 \%$ (CNN Türk 2017). Hence, 15\% of the eligible population appeared to be indifferent regarding the constitutional amendment. Under the new proposal, apart from the green and red balls indicating 'yes' and 'no', respectively, there could be a third type of ball, say white, signifying indifference. The urn's contents would therefore be comprised of $15 \%$ white balls (capturing the indifferent population), $43.7 \%$ $(51.4 \%$ of $85 \%)$ green balls (indicating a 'yes' vote), and $41.3 \%(48.6 \%$ of $85 \%)$ red balls (signifying a 'no' vote). If, in the first stage, a green or red ball is drawn, that would simply translate into the introduction of policy or maintenance of the status quo, respectively. However, if a white ball is drawn in the first stage, the procedure would go to the next stage where the urn contains an equal proportion of green and red balls, indicating equal probability of policy change and status quo and, hence, indifference between these two policy choices. This procedure is depicted in Fig. 1. Overall, this refined procedure leads to the situation where an ex-ante probability of introducing the presidential system in Turkey would equal $51.2 \%$ instead of $51.4 \%$. This slight drop reflects that $15 \%$ of population is indifferent between changing the system and preserving the status quo.

\footnotetext{
6 The assumption of indifference driven abstention under the Frey's proposal is likely to hold. First, as claimed above, the random procedure will tend to minimize non-voting due lack of 'my vote does not count' rationale. Secondly, the abstention due to alienation (i.e. policy choices being too distant from voters to justify the cost of voting) is unlikely in salient referendums, such as Brexit or the Turkish Constitutional Referendum.
} 


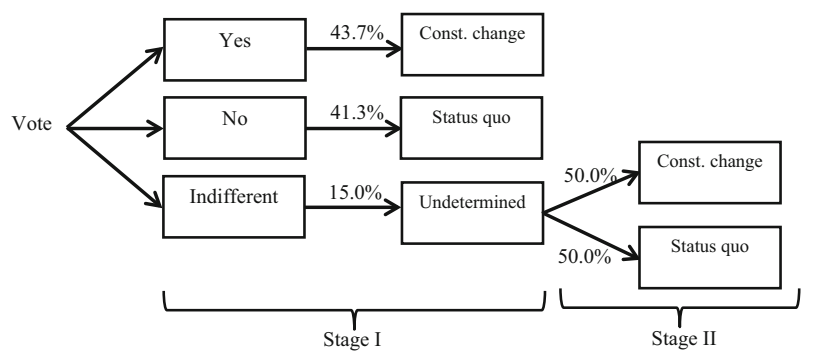

Fig. 1 Two stage randomization procedure Source: own figure

Accounting for the turnout or, in other words, abstention, would make disparities between vote shares less extreme. An acute example of this may be the 2015 referendum on single-member districts and public funding of political parties held in Poland. ${ }^{7}$ In this referendum, $78.8 \%$ of voting Poles supported the introduction of a winner-takes-all system, and $17.4 \%$ were in favor of public funding for political parties (PKW 2015). At first glance, these results may be appealing, yet strikingly the turnout in this referendum equaled merely $7.8 \%$, which indicates that $92.2 \%$ of Poles were somewhat indifferent on these policy options. If this referendum had any binding and decisive nature (one should bear in mind that this referendum had merely a consultative nature), an ex-ante probability of adopting a winner-takes-all system would be approx. 52.2\%, instead of $78.8 \%$, while the probability of maintaining public funding of political parties would be $47.5 \%$, instead of $17.4 \%$.

One could further consider combining Frey's proposal 6.8 of lots with weights distributed by the vote share, with proposal 6.6 stating that "old persons can have a higher vote weight than young persons with regard to constitutional decisions on the future rules of the game". A system could be therefore designed where votes of given communities (or municipalities) are adjusted for weights derived from their demographic structure, with a larger share of the population above 65 years or a larger share of retired population translated into larger weights. Applying this refined proposal to the constitutional referendum in Turkey would arguably lead to somewhat higher support for the presidential system of governance, as the rural and small-town regions, which were predominantly in favor of the constitutional amendment, are at the same time those regions where demographic indicators are skewed toward the older population (BBC 2017).

Yet another extension of Bruno Frey's proposal could be the application of weighted lots to determine policy choices by parliaments. A random procedure with ex-ante probabilities as determined by vote shares of members of parliament would readily take into account the size of the opposition and, hence, should be considered as a fair policy process [it needs to be stressed that this could also be achieved by the implementation of the randomized decision rule as suggested by Holler (1985), and Berg and Holler (1986)]. The following example illustrates the context in which this procedure could be particularly valuable. Figure 2 presents a distribution of the

\footnotetext{
7 Another question asked in the 2015 referendum referred to whether, in case of legal uncertainty, the law should be interpreted in favor of a taxpayer.
} 


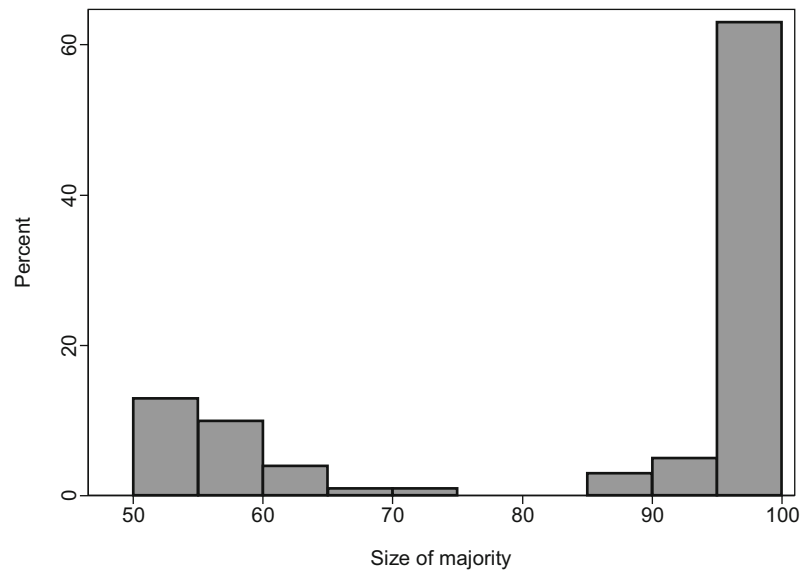

Fig. 2 Size of majority for legal acts enacted by the Sejm between December 1, 2016 and April 7, 2017 Source: own figure based on information extracted from www.sejm.gov.pl. Accessed on April 18, 2017

majority size for 100 legal acts enacted by the Polish Sejm (the lower chamber of the parliament) between December 1, 2016 and April 7, 2017. The distribution is clearly bimodal with some $60 \%$ of acts enacted by a majority of $95 \%$ and roughly $30 \%$ of acts being voted in by a slim majority of 50-60\%. The latter group arguably comprises those legal acts which are the most salient and involve ideologically complex issues.

Under the current parliamentary situation, the governing 'Law and Justice' party can in practice enact any law without considering the view from the opposition, as it holds more than $50 \%$ (235 out of 460) of the seats in the Sejm. A random procedure as defined in Frey's proposal 6.8 could be appealing and, by some, considered fair. This is particularly appealing if one bears in mind the fact that 'Law and Justice' obtained $37.6 \%$ of the popular support, but due to the specificity of the electoral system (d'Hondt system and 5\% electoral threshold), this support was translated into more than $50 \%$ of seats in the Sejm. ${ }^{8}$ Hence, laws enacted by 'Law and Justice' do not necessarily reflect what the majority of the population wants. The application of a random procedure would result in the promulgation of almost each legal act supported by all parties (acts would enjoy close to unanimous approval), but only slightly more than $50 \%$ of acts which are supported exclusively by 'Law and Justice'. This would arguably lead to a less controversial policy-making and less demonstrations against the current Polish government. Moreover, the application of a random procedure to the parliament's decision-making would also be less costly than the Swiss type of direct democracy institutions.

This short comment aimed at extending Bruno Frey's ideas on a democracy of the future as well as stimulating further discussion on this important topic. It is acknowledged that by and large the arguments presented by Bruno Frey and

\footnotetext{
8 One should note that Frey's proposal 6.9 on aleatoric democracy would minimize the likelihood of large disproportionalities between the shares of votes and seats, in particular when the number of randomly elected representatives is large.
} 
extensions offered here remain theoretical. One cannot overlook, however, the possibility that in the near future some local governments, particularly in federal countries, or even central governments will start experimenting with some of these ideas.

Open Access This article is distributed under the terms of the Creative Commons Attribution 4.0 International License (http://creativecommons.org/licenses/by/4.0/), which permits unrestricted use, distribution, and reproduction in any medium, provided you give appropriate credit to the original author(s) and the source, provide a link to the Creative Commons license, and indicate if changes were made.

\section{References}

Adams, J., Dow, J., \& Merrill, S., III. (2006). The political consequences of alienation-based and inidifference-based voter abstention: Applications to Presidential elections. Political Behavior, 28(1), 65-86.

BBC (2017). Recep Tayyip Erdogan: Turkey's pugnacious president. Published on April 17, 2017. Available at http://www.bbc.com/news/world-europe-13746679. Accessed 19 April 2017.

Berg, S., \& Holler, M. J. (1986). Randomized decision rules in voting games: a model for strict proportional power. Quality \& Quantity, 20, 419-429.

Blume, L., Hayo, B., \& Voigt, S. (2014). Correlates and Determinants of Direct Democracy. Available https://papers.ssrn.com/sol3/papers.cfm?abstract_id=2542156. Accessed 18 April 2017.

CNN Türk (2017). Results of the Turkish constitutional referendum. http://www.cnnturk.com/ referandum-2017. Accessed 19 April 2017.

Dodge, R. V. (2012). Schelling's game theory. How to make decisions (pp. 243-256). Oxford: Oxford University Press.

Holler, M. J. (1985). Strict proportional power in voting bodies. Theory and Decision, 19(3), 249-258.

PKW (2015). Referendum Ogólnokrajowe 6 września 2015. Available at http://referendum2015.pkw.gov. pl/341_Polska. Accessed 18 April 2017.

Tsebelis, G., \& Money, J. (1995). Bicameral negotiations: The navette system in France. British Journal of Political Science, 25(1), 101-129.

Tsebelis, G., \& Rasch, B. E. (1995). Patterns of Bicameralism. In H. Doering (Ed.), Parliaments and majority rule in western Europe (pp. 365-390). New York: St. Martin's.

Zipp, J. (1985). Perceived representativeness and voting: An assessment of the impact of "choices" vs. "echoes". The American Political Science Review, 79(1), 50-61. 